\title{
Interim Status Report on Lead-Cooled Fast Reactor (LFR) Research and Development
}

Nuclear Engineering Division 


\begin{abstract}
About Argonne National Laboratory
Argonne is a U.S. Department of Energy laboratory managed by UChicago Argonne, LLC under contract DE-AC02-06CH11357. The Laboratory's main facility is outside Chicago, at 9700 South Cass Avenue, Argonne, Illinois 60439. For information about Argonne, see www.anl.gov.
\end{abstract}

\title{
Availability of This Report
}

This report is available, at no cost, at http://www.osti.gov/bridge. It is also available on paper to the U.S. Department of Energy and its contractors, for a processing fee, from:

U.S. Department of Energy

Office of Scientific and Technical Information

P.O. Box 62

Oak Ridge, TN 37831-0062

phone (865) 576-8401

fax (865) 576-5728

reports@adonis.osti.gov

\begin{abstract}
Disclaimer
This report was prepared as an account of work sponsored by an agency of the United States Government. Neither the United States Government nor any agency thereof, nor UChicago Argonne, LLC, nor any of their employees or officers, makes any warranty, express or implied, or assumes any legal liability or responsibility for the accuracy, completeness, or usefulness of any information, apparatus, product, or process disclosed, or represents that its use would not infringe privately owned rights. Reference herein to any specific commercial product, process, or service by trade name, trademark, manufacturer, or otherwise, does not necessarily constitute or imply its endorsement, recommendation, or favoring by the United States Government or any agency thereof. The views and opinions of document authors expressed herein do not necessarily state or reflect those of the United States Government or any agency thereof, Argonne National Laboratory, or UChicago Argonne, LLC.
\end{abstract}




\title{
Interim Status Report on Lead-Cooled Fast Reactor (LFR) Research and Development
}

\author{
by \\ C.P. Tzanos, ${ }^{1}$ J.J. Sienicki, ${ }^{1}$ A. Moisseytsev, ${ }^{1}$ C.F. Smith, ${ }^{2}$ M.de Caro, ${ }^{2}$ \\ W.G. Halsey, ${ }^{2}$ N. Li, ${ }^{3}$ P. Hosemann, ${ }^{3}$ J. Zhang, ${ }^{3}$ and A. Bolind ${ }^{4}$ \\ ${ }^{1}$ Nuclear Engineering Division, Argonne National Laboratory \\ 'Lawrence Livermore National Laboratory \\ ${ }^{3}$ Los Alamos National Laboratory \\ ${ }^{4}$ University of Illinois, Urbana-Champaign \\ edited by \\ James J. Sienicki \\ Nuclear Engineering Division, Argonne National Laboratory
}

March 31, 2008 


\section{Table of Contents}

Abstract

1. Argonne National Laboratory

1.1. Introduction

1.2. Burnup Simulations

1.3. Reactivity Coefficients

1.4. Control Rod Worth Requirements and Control Rod Reactivity

1.5. Summary of Core Concept Development Analyses

1.6. References

iv

1

1

2

8

10

12

13

14

14

2.1. International Interactions

2.2. ODS Steels in Corrosive Lead-Bismuth Eutectic

15

2.2.1. LBE-Cooled Fast Reactor Hot Spot Simulation: Low-Cr ODS Steels

2.2.2. Improved Corrosion Resistance in Al-Diffusion Treated

F/M Steels

16

2.2.3. Low-Cr ODS and F/M Steels with Modified Surface

Structure

2.2.4. Corrosion Resistant High-Cr ODS Ferritic Steels

2.3. References

3. Los Alamos National Laboratory 21

3.1. Introduction 21

3.2. Published or Submitted Papers 21

3.3. DELTA PbO Experiment 24

3.4. Effects of Oxides on Steels and Oxygen in LBE on Heat Transfer 24

3.5. Long-Term Oxidation/Corrosion Performance of Candidate Steels in $\mathrm{LBE}$ and $\mathrm{Pb}$

25

4. Acknowledgements 


\section{List of Figures}

Figure 1-1. Reactor Active Core Configuration : $\mathrm{P}=$ Primary Control Rod; $\mathrm{S}=$ Secondary Control Rod; 1,2,3 = Enrichment Zones.

Figure 2-1. Hot spot simulation of temperature changes during LFR reactor operation, and SEM of ODS surface cross-section showing strong dissolution attack of the specimen exposed to LBE with $10^{-6} \mathrm{wt} \%$ oxygen content for $4800 \mathrm{~h}$ at $550-650{ }^{\circ} \mathrm{C}$ every $800 \mathrm{~h}$.

Figure 2-2. Optical micrograph of cross-sections of Al-diffusion-treated JPCA specimen after corrosion test in LBE at 450 and $550^{\circ} \mathrm{C}$ for $3000 \mathrm{~h}$

Figure 2-3. SEM cross section of GESA Surface Treated E911 specimen after exposure to flowing $\operatorname{LBE}\left(550^{\circ} \mathrm{C}, 2000 \mathrm{~h}\right)$ and line scans of elements.

Figure 2-4. Coolant Temperature/Burnup of Next Generation Nuclear Systems, taken from [7].

Figure 2-5. Corrosion resistance of high-Cr ODS steel (19Cr-4Al) at high temperature $\left(650^{\circ} \mathrm{C}\right)$ exposed to $\mathrm{LBE}$ for $10,000 \mathrm{~h}$ with an oxygen content of 10-6 Wt $\% \mathrm{O}_{2}$, taken from Reference [7].

Figure 3-1. Long-Term Behavior of Steels in Flowing LBE with a Velocity of 1 $\mathrm{m} / \mathrm{s}$, an Oxygen Concentration of 0.01-0.02 ppm, and a Temperature of $470{ }^{\circ} \mathrm{C}$ .26

Figure 3-2. Long-Term Behavior of Steels given in LBE at a Velocity of 1.9 and $0.5 \mathrm{~m} / \mathrm{s}$, an Oxygen Concentration of 0.01, 0.02-0.03 ppm, and a Temperature of $550{ }^{\circ} \mathrm{C}$. 


\section{List of Tables}

Table 1-1. Initial Core Parameters Assumed ............................................................ 2

Table 1-2. Isotopic Mass Fractions of Fresh Fuel.......................................................... 3

Table 1-3. Reactor Performance versus Cycle Length Calculated for R-Z Core Geometry

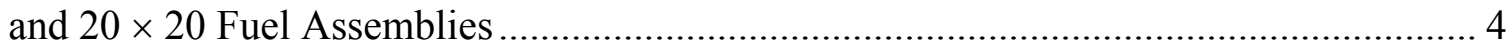
Table 1-4. Reactor Performance versus Cycle Length Calculated for Three-Dimensional Core Geometry and $10 \times 10$ Fuel Assemblies ......................................................... 8

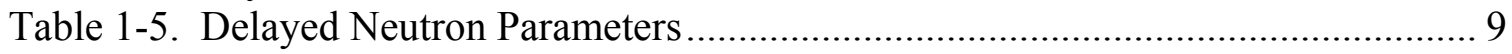

Table 1-6. Selected Reactivity Feedback Coefficients at BOEC ................................... 9

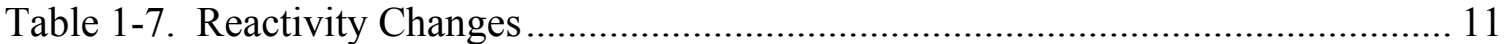

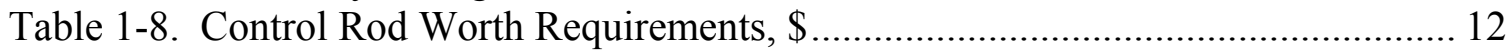

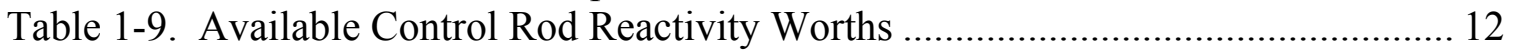

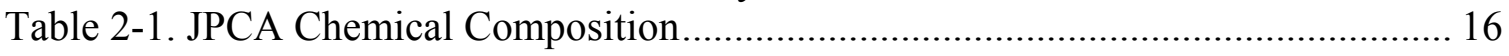




\begin{abstract}
This report discusses the status of Lead-Cooled Fast Reactor (LFR) research and development carried out during the first half of FY 2008 under the U.S. Department of Energy Generation IV Nuclear Energy Systems Initiative. Lead-Cooled Fast Reactor research and development has recently been transferred from Generation IV to the Reactor Campaign of the Global Nuclear Energy Partnership (GNEP). Another status report shall be issued at the end of FY 2008 covering all of the LFR activities carried out in FY 2008 for both Generation IV and GNEP. The focus of research and development in FY 2008 is an initial investigation of a concept for a LFR Advanced Recycling Reactor (ARR) Technology Pilot Plant (TPP)/demonstration test reactor (demo) incorporating features and operating conditions of the European Lead-cooled SYstem (ELSY) 600 MWe lead $(\mathrm{Pb})$-cooled LFR preconceptual design for the transmutation of waste and central station power generation, and which would enable irradiation testing of advanced fuels and structural materials. Initial scoping core concept development analyses have been carried out for a $100 \mathrm{MWt}$ core composed of sixteen open-lattice 20 by 20 fuel assemblies largely similar to those of the ELSY preconceptual fuel assembly design incorporating fuel pins with mixed oxide (MOX) fuel, central control rods in each fuel assembly, and cooled with $\mathrm{Pb}$ coolant. For a cycle length of three years, the core is calculated to have a conversion ratio of 0.79 , an average discharge burnup of 108 $\mathrm{MWd} / \mathrm{kg}$ of heavy metal, and a burnup reactivity swing of about 13 dollars. With a control rod in each fuel assembly, the reactivity worth of an individual rod would need to be significantly greater than one dollar which is undesirable for postulated rod withdrawal reactivity insertion events. A peak neutron fast flux of $2.0 \times 10^{15}\left(\mathrm{n} / \mathrm{cm}^{2}-\mathrm{s}\right)$ is calculated. For comparison, the 400 MWt Fast Flux Test Facility (FFTF) achieved a peak neutron fast flux of $7.2 \times 10^{15}\left(\mathrm{n} / \mathrm{cm}^{2}-\mathrm{s}\right)$ and the initially $563 \mathrm{MWt}$ PHENIX reactor attained $2.0 \times 10^{15}\left(\mathrm{n} / \mathrm{cm}^{2}-\mathrm{s}\right)$ before one of three intermediate cooling loops was shut down due to concerns about potential steam generator tube failures. The calculations do not assume a test assembly location for advanced fuels and materials irradiation in place of a fuel assembly (e.g., at the center of the core); the calculations have not examined whether it would be feasible to replace the central assembly by a test assembly location. However, having only fifteen driver assemblies implies a significant effect due to perturbations introduced by the test assembly. The peak neutron fast flux is low compared with the fast fluxes previously achieved in FFTF and PHENIX. Furthermore, the peak neutron fluence is only about half of the limiting value $\left(4 \times 10^{23} \mathrm{n} / \mathrm{cm}^{2}\right)$ typically used for ferritic steels. The results thus suggest that a larger power level (e.g., $400 \mathrm{MWt}$ ) and a larger core would be better for a TPP based upon the ELSY fuel assembly design and which can also perform irradiation testing of advanced fuels and materials. In particular, a core having a higher power level and larger dimensions would achieve a suitable average discharge burnup, peak fast flux, peak fluence, and would support the inclusion of one or more test assembly locations. Participation in the Generation IV International Forum Provisional System Steering Committee for the LFR is being maintained throughout FY 2008. Results from the analysis of samples previously exposed to flowing lead-bismuth eutectic (LBE) in the DELTA loop are summarized and a model for the oxidation/corrosion kinetics of steels in heavy liquid metal coolants was
\end{abstract}


applied to systematically compare the calculated long-term (i.e., following several years of growth) oxide layer thicknesses of several steels. 


\section{Argonne National Laboratory}

\subsection{Introduction}

An effort has been initiated to develop a preconceptual core design for a Lead-Cooled Fast Reactor (LFR) Technology Pilot Plant (TPP) demonstration reactor (demo) incorporating key features of the European Lead-cooled SYstem (ELSY) $600 \mathrm{MWe}$ $(1500 \mathrm{MWt})$ central station LFR for the transmutation of radioactive waste together with electricity generation [1 and 2]. This effort is a genuine collaboration between Argonne National Laboratory (ANL) and Ente Nazionale per le Nuove Tecnologie, 1'Energia e l'Ambiente (ENEA) as well as Del Fungo Giera Energia (DFGE) founded by Luciano Cinotti. The ELSY project has been investigating an open square-lattice core composed of removable square fuel assemblies with oxide fuel and $\mathrm{Pb}$ coolant. Based upon the ELSY current conditions as well as consultation between ANL, ENEA, and DFGE [3], the preliminary conditions listed in Table 1-1 have been assumed for the TPP. A power level of $100 \mathrm{MWt}$ has been selected. The cladding utilizes an existing material, T91 (a modified $9 \mathrm{Cr}-1$ Mo steel), for the cladding at relatively low temperatures. However, the T91 cladding will be "aluminized" using the process currently applied in the GESA IV apparatus at the Forschungszentrum Karlsruhe. It has recently been demonstrated [4] that aluminizing protects $\mathrm{T} 91$ steel cladding from LBE corrosive attack at velocities at least as high as $3 \mathrm{~m} / \mathrm{s}$ and temperatures as high as $550{ }^{\circ} \mathrm{C}$. In contrast, without aluminizing, T91 may be protected at velocities only less than $\sim 1 \mathrm{~m} / \mathrm{s}$. The TPP core inlet and outlet temperatures are fixed at $400{ }^{\circ} \mathrm{C}$ and $480{ }^{\circ} \mathrm{C}$, respectively. Other key features of ELSY include a pool vessel configuration, integral spiral tube steam generators and $\mathrm{Pb}$ mechanical pumps installed in the hot leg of the circuit, simplification of the internal structures, lack of steel shielding structure to reduce the neutron flux at the reactor vessel, a superheated steam power converter, and two-dimensional seismic isolation.

This work presents the results of preconceptual core design calculations representing a starting point in an iterative design process for the core of a $100 \mathrm{MWt}$ TPP. The calculations include: burnup simulations in $\mathrm{R}-\mathrm{Z}$ and three-dimensional geometry to determine the fuel cycle length and provide an initial estimate of the performance of an equilibrium core; the development of an initial core layout; estimates of reactivity feedback coefficients with emphasis on those needed to determine control rod requirements; and an estimate of control rod reactivity worth requirements for the primary and secondary reactivity control and shutdown systems. 
Table 1-1. Initial Core Parameters Assumed

\begin{tabular}{|l|l|}
\hline Reactor Power, $\mathrm{MWt}$ & 100 \\
\hline Fuel & MOX \\
\hline Pellet density & 0.95 of theoretical \\
\hline Theoretical density of $\mathrm{UO}_{1.95}$ at $20{ }^{\circ} \mathrm{C}, \mathrm{g} / \mathrm{cc}$ & 10.95 \\
\hline Theoretical density of $\mathrm{PuO}_{1.95}$ at $20{ }^{\circ} \mathrm{C}, \mathrm{g} / \mathrm{cc}$ & 11.46 \\
\hline Peak linear heat rate, $\mathrm{W} / \mathrm{cm}$ & 320.0 \\
\hline Peak pin power/Average pin power & 1.15 \\
\hline Core inlet temperature, ${ }^{\circ} \mathrm{C}$ & 400 \\
\hline Core outlet temperature, ${ }^{\circ} \mathrm{C}$ & 480 \\
\hline Peak cladding temperature, ${ }^{\circ} \mathrm{C}$ & 550 \\
\hline Maximum coolant velocity, $\mathrm{m} / \mathrm{s}$ & $<2.0$ \\
\hline Peak burnup, MWd/kg & 100 \\
\hline Fuel Assembly (open square lattice, $20 \times \mathrm{x} 20)$ \\
\hline Clearance between FAs, $\mathrm{mm}$ & 4.0 \\
\hline Pellet diameter, mm & 9.0 \\
\hline Cladding thickness, mm & 0.6 \\
\hline Cladding/pellet gap, mm & 0.16 \\
\hline Pin pitch, mm & 13.0 \\
\hline Fuel pin active length, cm & 80.0 \\
\hline
\end{tabular}

\subsection{Burnup Simulations}

Based upon initial ELSY core analyses, an open core assembly having 20 x 20 pins arranged on a square pitch was initially assumed in which four corner pins provide structural support and the space of the four central pins is used for a control rod. Other design parameters are shown in Table 1-1. Aluminum oxide $\left(\mathrm{Al}_{2} \mathrm{O}_{3}\right)$ that would be present as thin layers on the cladding following aluminizing was not modeled in the calculations. With these design parameters, about fifteen assemblies are needed to produce a power of $100 \mathrm{MWt}$. Although this small number of assemblies may be impractical and the size of an individual assembly may need to be reduced, for the initial R-Z REBUS [5] simulations, sixteen core assemblies were assumed. Based on preliminary information about the ELSY preconceptual design [3], the following assumptions were made: below the core region there is a $90 \mathrm{~cm}$ plenum region with volume fractions of 0.6932 coolant, 0.08443 structure, and 0.22237 void, and below this region there is a $60 \mathrm{~cm}$ "foot-assembly" region with volume fractions of 0.794 coolant and 0.206 structure. Above the core, there is a $10 \mathrm{~cm}$ "top-assembly" region with volume fractions of 0.794 coolant and 0.206 structure, and above this region there is a $200 \mathrm{~cm}$ "top-plenum" region with volume fractions of 0.6932 coolant, 0.08443 structure, and 0.22237 void. The core is surrounded by a $64 \mathrm{~cm}$ thick $\mathrm{Pb}$ radial reflector. It was 
also assumed that the pins are separated by grid spacers similar to the approach followed in Light Water Reactors (LWRs).

Equilibrium REBUS burnup simulations were performed with cycle lengths of 90, 180, 365, and 1095 days. A 33-group cross section set was generated for a lead-cooled core fueled with mixed oxide (MOX) fuel. The fuel residence time was three cycles. Thus, at the beginning of the equilibrium cycle (BOEC), one third of the fuel is fresh, one third has burned for one cycle, and the other third has burned for two cycles. At the end of the equilibrium cycle (EOEC), one third of the fuel has burned for one cycle, one third has burned for two cycles, and the other third has burned for three cycles. The fresh fuel was assumed to be fabricated from spent LWR fuel having the composition presented in Table 1-2. The only minor actinide present in the fresh fuel is Am-241 which is the product of $\mathrm{Pu}-241$ decay.

\section{Table 1-2. Isotopic Mass Fractions of Fresh Fuel}

\begin{tabular}{|c|c|}
\hline $\mathrm{Pu}-238$ & 0.026567 \\
\hline $\mathrm{Pu}-239$ & 0.527327 \\
\hline $\mathrm{Pu}-240$ & 0.251494 \\
\hline $\mathrm{Pu}-241$ & 0.109052 \\
\hline $\mathrm{Pu}-242$ & 0.074552 \\
\hline $\mathrm{Am}-241$ & 0.011008 \\
\hline $\mathrm{U}-234$ & 0.000030 \\
\hline $\mathrm{U}-235$ & 0.004040 \\
\hline $\mathrm{U}-238$ & 0.995830 \\
\hline
\end{tabular}

As Table 1-3 shows, the conversion ratio decreases with the fuel cycle length from 0.8695 to 0.7881 . The burnup reactivity swing increases from $0.323 \% \Delta \mathrm{k}(0.89$ dollars $)$ to $4.948 \% \Delta \mathrm{k}$ (about 13 dollars) and the average discharge burnup increases from 8.89 $\mathrm{MWd} / \mathrm{kg}$ to $108.2 \mathrm{MWd} / \mathrm{kg}$. 
Table 1-3. Reactor Performance versus Cycle Length Calculated for R-Z Core Geometry and $20 \times 20$ Fuel Assemblies

\begin{tabular}{|c|c|c|c|c|}
\hline Cycle length, days & 90 & 180 & 365 & 1095 (3years) \\
\hline Fuel Form & MOX & MOX & MOX & MOX \\
\hline Fissile Material & $\mathrm{PuO}_{1.95}$ & $\mathrm{PuO}_{1.95}$ & $\mathrm{PuO}_{1.95}$ & $\mathrm{PuO}_{1.95}$ \\
\hline Reactor power, MWt & 100 & 100 & 100 & 100 \\
\hline Pin diameter, $\mathrm{mm}$ & 10.52 & 10.52 & 10.52 & 10.52 \\
\hline Pitch-to-diameter ratio & 1.236 & 1.236 & 1.236 & 1.236 \\
\hline Cladding thickness, $\mathrm{mm}$ & 0.6 & 0.6 & 0.6 & 0.6 \\
\hline Core height at $293 \mathrm{~K}, \mathrm{~cm}$ & 80.0 & 80.0 & 80.0 & 80.0 . \\
\hline Core radius at $293 \mathrm{~K}, \mathrm{~cm}$ & 59.019 & 59.019 & 59.019 & 59.016 \\
\hline Number of pins per assembly & 400 & 400 & 400 & 400 \\
\hline \multicolumn{5}{|l|}{ Control rods } \\
\hline Clearance between FAs, mm & 4 & 4 & 4 & 4 \\
\hline \multicolumn{5}{|l|}{$\begin{array}{l}\text { Core Material Volume } \\
\text { Fractions at } 293 \mathrm{~K}\end{array}$} \\
\hline Fuel & 0.3646 & 0.3646 & 0.3646 & 0.3646 \\
\hline Coolant & 0.4896 & 0.4896 & 0.4896 & 0.4896 \\
\hline Structure & 0.1194 & 0.1194 & 0.1194 & 0.1194 \\
\hline Bond & 0.0264 & 0.0264 & 0.0264 & 0.0264 \\
\hline $\begin{array}{l}\text { Fuel enrichment, \% (Inner } \\
\text { core/middle core/outer core) }\end{array}$ & $\begin{array}{l}15.352 / 19.497 / \\
23.796\end{array}$ & $\begin{array}{l}15.695 / 19.619 / \\
23.543\end{array}$ & $\begin{array}{l}15.926 / 20.226 / \\
24.685\end{array}$ & $\begin{array}{l}17.846 / 23.200 / \\
28.554\end{array}$ \\
\hline Conversion ratio & 0.8695 & 0.8655 & 0.8488 & 0.7881 \\
\hline $\begin{array}{l}\text { Fissionable loading at BOEC, } \\
\mathrm{kg}\end{array}$ & 2961.5 & 2961.7 & 2962.5 & 2966.2 \\
\hline $\begin{array}{l}\text { Peak power density } \\
\text { (BOEC/EOEC), } \mathrm{kW} / \mathrm{L}\end{array}$ & $141.7 / 140.7$ & $143.8 / 145.4$ & $141.8 / 145.0$ & $140.7 / 146.4$ \\
\hline $\begin{array}{l}\text { Discharge burnup (average), } \\
\mathrm{MWd} / \mathrm{kg}\end{array}$ & 8.89 & 17.78 & 36.06 & 108.2 \\
\hline $\begin{array}{l}\text { Burnup reactivity swing, }(\% \\
\Delta \mathrm{k}, \mathrm{BOEC-EOEC)}\end{array}$ & 0.323 & 0.653 & 1.367 & 4.948 \\
\hline $\begin{array}{l}\text { Power peaking factor } \\
\text { (BOEC/EOEC) }\end{array}$ & $1.269 / 1.260$ & $1.287 / 1.302$ & $1.270 / 1.299$ & $1.259 / 1.311$ \\
\hline Peak linear power, W/cm & 239.0 & 245.6 & 244.9 & 247.6 \\
\hline $\begin{array}{l}\text { Peak Flux (BOEC/EOEC), } \\
10^{15}\left(\mathrm{n} / \mathrm{cm}^{2}-\mathrm{s}\right)\end{array}$ & $2.02 / 2.04$ & $2.05 / 2.08$ & $2.01 / 2.08$ & $1.90 / 2.08$ \\
\hline
\end{tabular}


A desired feature for the TPP is a high neutron flux to provide the ability to test new fuels to high burnups over a reasonable exposure time. The preconceptual core design provides a peak flux of about $2.0 \times 10^{15}\left(\mathrm{n} / \mathrm{cm}^{2}-\mathrm{s}\right)$. For comparison, the Fast Flux Test Facility (FFTF) generated a peak flux of $7.2 \times 10^{15}\left(\mathrm{n} / \mathrm{cm}^{2}-\mathrm{s}\right)$. The FFTF had a power of $400 \mathrm{MWt}$, a peak linear power of $420 \mathrm{~W} / \mathrm{cm}$, an average fuel burnup of $45 \mathrm{MWd} / \mathrm{kg}$, a refueling interval of 100 days, a pin diameter of $5.8 \mathrm{~mm}$, a pin pitch-to-diameter ratio of 1.24 , and a fuel volume fraction of $35 \%$.

Because the oxide layer that protects reactor structures from corrosive attack by heavy liquid metal coolant is reduced or removed if the coolant velocity exceeds a certain value, a criterion has been specified in Table 1-1 that the maximum coolant velocity remains below $2 \mathrm{~m} / \mathrm{s}$. For the present core, the average core coolant velocity is $1.33 \mathrm{~m} / \mathrm{s}$. Assuming a grid spacer thickness of $1 \mathrm{~mm}$, the coolant velocity in the grid spacer region is about $2.0 \mathrm{~m} / \mathrm{s}$. The velocities are low enough that with aluminizing the oxide layer would not be expected to be removed by the flowing $\mathrm{Pb}$.

For an assembly design having $20 \times 20$ pins, fifteen assemblies are needed to produce a power of $100 \mathrm{MWt}$. This small number of assemblies results in a large reactivity worth per assembly, it may not be flexible as a test reactor (few locations for test assemblies), and it may not be flexible in the design of the control rod system. Therefore, the size of an assembly was reduced to $10 \times 10$ pins, and a core layout was generated, as shown in Figure 1-1 having 60 fuel assemblies and nine control rod assemblies (primary plus secondary). The reactor core is surrounded by a lead radial reflector having a thickness of five assembly-rows. Thus, the core incorporates control rods in place of entire assemblies rather than within individual assemblies as in the ELSY preconceptual design. 


\begin{tabular}{|c|c|c|c|c|c|c|c|c|}
\hline & & 3 & 3 & 3 & 3 & 3 & & \\
\hline & 3 & 3 & 2 & $P$ & 2 & 3 & 3 & \\
\hline 3 & 3 & $S$ & 1 & 1 & 1 & $S$ & 3 & 3 \\
\hline 3 & 2 & 1 & 1 & 1 & 1 & 1 & 2 & 3 \\
\hline 3 & $P$ & 1 & 1 & $P$ & 1 & 1 & $P$ & 3 \\
\hline 3 & 2 & 1 & 1 & 1 & 1 & 1 & 2 & 3 \\
\hline 3 & 3 & $S$ & 1 & 1 & 1 & $S$ & 3 & 3 \\
\hline & 3 & 3 & 2 & $P$ & 2 & 3 & 3 & \\
\hline & & 3 & 3 & 3 & 3 & 3 & & \\
\hline
\end{tabular}

Figure 1-1. Reactor Active Core Configuration : $\mathbf{P}=$ Primary Control Rod; $\mathbf{S}=$ Secondary Control Rod; 1,2,3 = Enrichment Zones. 
For a small reactor core with three enrichment zones for radial power shaping, a twocycle scheme is a more realistic approximation to an equilibrium-cycle scheme than a three-cycle scheme. Equilibrium REBUS burnup simulations were performed in a 3dimensional XYZ geometry with cycle lengths of 180 and 365 days. The fuel residence time was two cycles.

As Table 1-4 shows, for a cycle length of 365 days, the burnup reactivity swing is 1.951 $\% \Delta \mathrm{k}$ (5.3 dollars). For a five rod primary control system, this burnup reactivity swing would require an inserted control rod worth per rod, of over 1 dollar. For a cycle length of 180 days, the burnup reactivity swing is $0.932 \% \Delta \mathrm{k}$ (2.5 dollars) which achieves an inserted control rod worth per rod of less than 1 dollar. A cycle length of 180 days was chosen as an initial design point to evaluate reactivity feedback coefficients. 
Table 1-4. Reactor Performance versus Cycle Length Calculated for ThreeDimensional Core Geometry and $10 \times 10$ Fuel Assemblies

\begin{tabular}{|c|c|c|}
\hline Cycle length, days & 180 & 365 \\
\hline Fuel Form & MOX & MOX \\
\hline Fissile Material & $\mathrm{PuO}_{1.95}$ & $\mathrm{PuO}_{1.95}$ \\
\hline Reactor power, MWt & 100 & 100 \\
\hline Pin diameter, $\mathrm{mm}$ & 10.52 & 10.52 \\
\hline Pitch-to-diameter ratio & 1.236 & 1.236 \\
\hline Clad thickness, mm & 0.6 & 0.6 \\
\hline Core height at $293 \mathrm{~K}, \mathrm{~cm}$ & 80.0 & 80.0 \\
\hline Core radius at $293 \mathrm{~K}, \mathrm{~cm}$ & 57.48 & 57.48 \\
\hline Number of pins per assembly & 100 & 100 \\
\hline \multicolumn{3}{|l|}{ Control rods } \\
\hline Clearance between FAs, mm & 4.0 & 4.0 \\
\hline \multicolumn{3}{|l|}{$\begin{array}{l}\text { Core Material Volume } \\
\text { Fractions at } 293 \mathrm{~K}\end{array}$} \\
\hline Fuel & 0.3494 & 0.3494 \\
\hline Coolant & 0.4951 & 0.4951 \\
\hline Structure & 0.1302 & 0.1302 \\
\hline Bond & 0.0253 & 0.0253 \\
\hline $\begin{array}{l}\text { Fuel enrichment, \% (Inner } \\
\text { core/middle core/outer core) }\end{array}$ & $\begin{array}{l}17.040 / 20.448 / \\
22.152 \\
\end{array}$ & $\begin{array}{l}17.507 / 21.008 / \\
22.759\end{array}$ \\
\hline Conversion ratio & 0.802 & 0.783 \\
\hline $\begin{array}{l}\text { Fissionable loading at BOEC, } \\
\mathrm{kg}\end{array}$ & 2693.6 & 2694.3 \\
\hline $\begin{array}{l}\text { Peak power density } \\
\text { (BOEC/EOEC), } \mathrm{kW} / \mathrm{L}\end{array}$ & $157.0 / 156.0$ & $156.6 / 154.8$ \\
\hline $\begin{array}{l}\text { Discharge burnup (average), } \\
\mathrm{MWd} / \mathrm{kg}\end{array}$ & 13.01 & 26.38 \\
\hline $\begin{array}{l}\text { Burnup reactivity swing, (\% } \\
\Delta \mathrm{k}, \mathrm{BOEC-EOEC)}\end{array}$ & 0.932 & 1.951 \\
\hline $\begin{array}{l}\text { Power peaking factor } \\
\text { (BOEC/EOEC) }\end{array}$ & $1.337 / 1.329$ & $1.334 / 1.318$ \\
\hline Peak linear power, W/cm & 265.4 & 264.7 \\
\hline $\begin{array}{l}\text { Peak Flux (BOEC/EOEC), } \\
10^{15}\left(\mathrm{n} / \mathrm{cm}^{2}-\mathrm{s}\right)\end{array}$ & $2.06 / 2.1$ & $2.04 / 2.10$ \\
\hline
\end{tabular}

\subsection{Reactivity Coefficients}

The atom densities computed by REBUS at BOEC conditions were used to compute reactivity feedback coefficients and control rod reactivity worths with the threedimensional diffusion code, DIF3D [6], and the perturbation theory code, VARI3D [7]. 
For these calculations, a cross-section set was generated that includes 33-group cross sections for a lead-cooled reactor: at operating conditions; with the coolant voided in the reactor core for the computation of the coolant void reactivity; at high fuel temperatures with the coolant present in the core, and with the coolant voided in the core for the calculation of the Doppler coeficient of reactivity (under conditions where the coolant is present as well as under conditions where the coolant is assumed voided); and with control rods inserted in the core for the calculation of control rod worths. Delayed neutron information was generated at BOEC conditions with the above 33-group cross section data set using the ANL perturbation code, VARI3D. This information is summarized in Table 1-5. VARI3D was also used with exact perturbation theory to compute the core coolant void reactivity, the coolant density reactivity, and the Doppler coefficient, $\left[\Delta \mathrm{k} / \ln \left(\mathrm{T}_{2} / \mathrm{T}_{1}\right)\right]$. They are presented in Table 1-6. At an average fuel operating temperature of $930{ }^{\circ} \mathrm{C}$, the computed Doppler coefficient gives a reactivity feedback coefficient of -0.035 cents $/{ }^{\circ} \mathrm{C}$. The core radial expansion coefficient is also significant for reactivity feedback effects. It has not yet been calculated and shall be included in a future report.

Table 1-5. Delayed Neutron Parameters

\begin{tabular}{|c|l|l|l|}
\hline Group & Fraction & Yield & Decay Constant \\
\hline 1 & $8.4864 \times 10^{-5}$ & $2.3413 \times 10^{-2}$ & $1.3413 \times 10^{-2}$ \\
\hline 2 & $6.9246 \times 10^{-4}$ & $1.9104 \times 10^{-1}$ & $3.0730 \times 10^{-2}$ \\
\hline 3 & $5.4088 \times 10^{-4}$ & $1.4922 \times 10^{-1}$ & $1.1736 \times 10^{-1}$ \\
\hline 4 & $1.2921 \times 10^{-3}$ & $3.5647 \times 10^{-1}$ & $3.0789 \times 10^{-1}$ \\
\hline 5 & $7.4366 \times 10^{-4}$ & $2.0517 \times 10^{-1}$ & $8.7991 \times 10^{-1}$ \\
\hline 6 & $2.7070 \times 10^{-4}$ & $7.4684 \times 10^{-2}$ & 2.9525 \\
\hline \multicolumn{3}{|l}{} & $3.6247 \times 10^{-3}$ \\
\hline Beta \\
Prompt neutron lifetime, s & $1.9110 \times 10^{-6}$ \\
\hline
\end{tabular}

Table 1-6. Selected Reactivity Feedback Coefficients at BOEC

\begin{tabular}{|l|l|}
\hline Coolant void reactivity, $\$$ & 3.27 \\
\hline Doppler coefficient & $-1.517 \times 10^{-3}$ \\
\hline Coolant density reactivity feedback coefficient, cents $/{ }^{\circ} \mathrm{C}$ & 0.055 \\
\hline Fuel axial expansion reactivity feedback coefficient, cents $/{ }^{\circ} \mathrm{C}$ & -0.064 \\
\hline Doppler reactivity feedback coefficient, cents $/{ }^{\circ} \mathrm{C}$ & -0.035 \\
\hline
\end{tabular}




\subsection{Control Rod Worth Requirements and Control Rod Reactivity}

Two independent safety-grade reactivity control systems are considered - a primary system and a secondary system. The primary system is required to have enough reactivity worth to bring the reactor from any operating state to a subcritical state at the refueling temperature with the most reactive control assembly stuck out of the reactor. The operating states, in terms of reactor power generation, are assumed to be bounded from above by operation at $115 \%$ nominal power, and from below, conservatively, by a zero power generation condition. Thus, the primary system, with the most reactive control assembly stuck out, has to compensate the reactivity effects of the fuel burnup, and the reactivity addition from the most reactive state between $100 \%$ power and $115 \%$ overpower to a subcritical state at the refueling temperature. This reactivity addition arises from thermal expansion effects and the Doppler reactivity effect derived from the fuel temperature change.

The secondary control rod system is required to shut down the reactor from any operating condition to the hot standby condition, without the insertion of any primary control assemblies. In the hot standby condition, the reactor power is zero, the coolant temperature is at the coolant inlet value at normal full power operation, and the fuel temperature is equal to that of the coolant. The secondary system does not have to compensate the burnup reactivity swing, but it should compensate the reactivity insertion due to the uncontrolled withdrawal of the primary control assembly that has the largest reactivity worth.

It is assumed that the refueling temperature is equal to the nominal core inlet temperature of $400{ }^{\circ} \mathrm{C}$. The core axial expansion and the Doppler reactivity are functions of the fuel temperature which is a function of the helium gap size between fuel and cladding. For fresh fuel (minimum gap conductivity), it is calculated that the average fuel temperature at normal operating conditions is $1219{ }^{\circ} \mathrm{C}$, and at $115 \%$ overpower conditions is 1341 ${ }^{\circ} \mathrm{C}$. For a closed gap (fuel in contact with the cladding), the corresponding temperatures are $930{ }^{\circ} \mathrm{C}$ and $1035^{\circ} \mathrm{C}$, respectively. Fuel expansion was computed from the equations [8],

$$
\begin{array}{rlrl}
L(T)= & L(273)\left(919734 \times 10^{-1}+9.802 \times 10^{-6} T\right. & & \\
& \left.-2.705 \times 10^{-10} T^{2}+4.391 \times 10^{-13} T^{3}\right), & & 273 K \leq T \leq 923 K \\
& & & \\
L(T)= & L(273)\left(9.9672 \times 10^{-1}+1.179 \times 10^{-5} T\right. & & \\
& \left.-2.429 \times 10^{-9} T^{2}+1.219 \times 10^{-12} T^{3}\right), & 923 \mathrm{~K}<T
\end{array}
$$

where $L(T)$ is the length at temperature T ( in degrees Kelvin) and $L(273)$ is the length at $273 \mathrm{~K}$.

Table 1-7 provides the reactivity changes for fresh fuel (open gap) and irradiated fuel (closed gap) that are relevant for the establishment of reactivity control requirements. 
The reactivity change with an open gap is larger and it is used in the estimation of the control rod requirements.

Table 1-8 provides the total control rod worth requirements, and their components, for the primary shutdown system. The reactivity fault is based on a maximum inserted individual control rod worth of $\$ 0.90$. This reactivity may be inserted in the event of an uncontrolled rod withdrawal. The other margins include: $\$ 1.0$ as shutdown margin, ATWS reactivity of $\$ 0.3$, and a fast rod runback of $\$ 0.5$.

The same rod design was used in the control assembly as in the fuel assembly, and natural boron was used in $\mathrm{B}_{4} \mathrm{C}$ as the neutron poison. Since larger rods can be used in the control assembly, at the next iteration of this design work, a redesigned control assembly could be used. Table 1-9 gives the available reactivity worth for the primary and secondary control rod systems. The reactivity worth of the secondary system is excessive. The number of rods can be reduced to two, or the secondary control assembly can be redesigned. For example, only the central section of the assembly could be used as a control rod while the remaining positions are occupied by fuel, similar to the configuration envisioned for ELSY.

Table 1-7. Reactivity Changes

\begin{tabular}{|l|c|c|}
\hline & Open Gap & Closed Gap \\
\hline $\begin{array}{l}\text { From } 115 \% \text { overpower to cold shutdown (expansion } \\
\text { effects only), \$ }\end{array}$ & 0.50 & 0.30 \\
\hline $\begin{array}{l}\text { Doppler reactivity change from } 115 \% \text { overpower to cold } \\
\text { shutdown, \$ }\end{array}$ & 0.37 & 0.28 \\
\hline Burnup reactivity swing, \$ & 2.57 & 2.57 \\
\hline Total, \$ & 3.44 & 3.15 \\
\hline
\end{tabular}


Table 1-8. Control Rod Worth Requirements, \$

\begin{tabular}{|l|c|}
\hline & \\
From $115 \%$ overpower to cold shutdown (expansion effects only) & 0.50 \\
\hline Doppler reactivity from 115\% overpower to cold shutdown & 0.37 \\
\hline Burnup reactivity swing & 2.57 \\
\hline Reactivity fault & 0.90 \\
\hline Uncertainties & \\
\hline - Temperature defect (20 \%) & 0.17 \\
\hline - Burnup reactivity swing (15\%) & 0.39 \\
\hline - Criticality prediction & 1.00 \\
\hline - Fissile loading & 1.00 \\
\hline - Refueling & 1.00 \\
\hline Total uncertainties (RMS) & 1.78 \\
\hline Other margins & 1.80 \\
\hline Overall total & 7.92 \\
\hline
\end{tabular}

Table 1-9. Available Control Rod Reactivity Worths

\begin{tabular}{|l|c|c|}
\hline & Primary & Secondary \\
\hline Number of control assemblies & 5 & 4 \\
\hline System reactivity worth, \$ & 18.77 & 25.74 \\
\hline Worth of one stuck assembly, \$ & 7.64 & 6.44 \\
\hline Reactivity worth available, \$ & 11.13 & 19.3 \\
\hline Maximum requirement, \$ & 7.92 & 0.87 \\
\hline Shutdown margin, \$ & 3.21 & 18.43 \\
& & \\
\hline
\end{tabular}

\subsection{Summary of Core Concept Development Analyses}

Initial scoping core concept development analyses have been carried out for a $100 \mathrm{MWt}$ core composed of sixteen open-lattice 20 by 20 fuel assemblies largely similar to those of the ELSY preconceptual fuel assembly design incorporating fuel pins with mixed oxide (MOX) fuel, central control rods in each fuel assembly, and cooled with $\mathrm{Pb}$ coolant. For a cycle length of three years, the core is calculated to have a conversion ratio of 0.79 , an average discharge burnup of $108 \mathrm{MWd} / \mathrm{kg}$ of heavy metal, and a burnup reactivity swing of about 13 dollars. With a control rod in each fuel assembly, the reactivity worth of an 
individual rod would need to be significantly greater than one dollar which is undesirable for postulated rod withdrawal reactivity insertion events. A peak neutron fast flux of 2.0 $\times 10^{15}\left(\mathrm{n} / \mathrm{cm}^{2}-\mathrm{s}\right)$ is calculated. For comparison, the $400 \mathrm{MWt}$ Fast Flux Test Facility (FFTF) achieved a peak neutron fast flux of $7.2 \times 10^{15}\left(\mathrm{n} / \mathrm{cm}^{2}-\mathrm{s}\right)$ and the initially 563 MWt PHENIX reactor attained $2.0 \times 10^{15}\left(\mathrm{n} / \mathrm{cm}^{2}-\mathrm{s}\right)$ before one of three intermediate cooling loops was shut down due to concerns about potential steam generator tube failures. The calculations do not assume a test assembly location for advanced fuels and materials irradiation in place of a fuel assembly (e.g., at the center of the core); the calculations have not examined whether it would be feasible to replace the central assembly by a test assembly location. However, having only fifteen driver assemblies implies a significant effect due to perturbations introduced by the test assembly. The peak neutron fast flux is low compared with the fast fluxes previously achieved in FFTF and PHENIX. Furthermore, the peak neutron fluence is only about half of the limiting value $\left(4 \times 10^{23} \mathrm{n} / \mathrm{cm}^{2}\right)$ typically used for ferritic steels. The results thus suggest that a larger power level (e.g., $400 \mathrm{MWt}$ ) and a larger core would be better for a TPP based upon the ELSY fuel assembly design and which can also perform irradiation testing of advanced fuels and materials. In particular, a core having a higher power level and larger dimensions would achieve a suitable average discharge burnup, peak fast flux, peak fluence, and would support the inclusion of one or more test assembly locations.

\subsection{References}

1. L. Cinotti, C. F. Smith, J. J. Sienicki, H. Alt Abderrahim, G. Benamati, G. Locatelli, S. Monti, H. Wider, D. Struwe, A. Orden, and I. S. Hwang, "The Potential of the LFR and the ELSY Project," Paper 7585, 2007 International Congress on Advances in Nuclear Power Plants (ICAPP 2007), Nice, France, May 13-18, 2007.

2. L. Cinotti, G. Locatelli, E. Malambu, H. Alt Abderrahim, S. Monti, G. Benamati, C. Artioli, and H. Wider, "The ELSY Project for a Sustainable Deployment of Nuclear Energy," $10^{\text {th }}$ ISTC SAC Seminar, Nizhny Novgorod, Russia, September 24-27, 2007.

3. S. Monti and C. Artioli, Personal Communication, ENEA, December 2007.

4. A. Weisenburger, A. Heinzel, G. Mueller, H. Muscher, AND A. Rusanov, "T91 Cladding Tubes with and without Modified FeCrAl Coatings Exposed in LBE at Different Flow, Stress and Temperature Conditions," IV International Workshop on Materials for HLM Cooled Reactors and Related Technologies, Rome, Italy, May 2123, 2007.

5. B. J. Toppel, "A User's Guide to the REBUS-3 Fuel Cycle Analysis Capability," ANL-83-2, Argonne National Laboratory (1983).

6. K. L. Derstine. "DIF3D: A Code to Solve One-, Two-, and Three-Dimensional Finite Difference Diffusion Theory Problems," ANL-82-64, Argonne National Laboratory (1984). 
7. C. H. Adams, Personal Communication, Argonne National Laboratory, March 2008.

8. J. J. Carbajo et. al., "A Review of the Thermophysical Properties of $\mathrm{MOX}$ and $\mathrm{UO}_{2}$ Fuels," Journal of Nuclear Materials, 299, 181-198 (2001).

\section{Lawrence Livermore National Laboratory}

\subsection{International Interactions}

During the reporting period, October 12007 to present, LLNL staff continued support to international interactions related to the LFR.

Biweekly telecons were planned and executed with potential international partners to discuss coordinating GIF-LFR activities including plans for a technology development/demonstration reactor.

LLNL organized and hosted a series of LFR meetings in November at the LLNL Washington DC office. These meetings included:

1) The GIF LFR Provisional System Steering Committee (PSSC) meeting (November 12) which conducted the normal committee business and, in addition, provided inputs to the LFR presentations before the GIF Experts and Policy Committee meetings in Korea in December.

2) A series of update briefings for DOE and other personnel on the status and accomplishments of the European Lead-cooled SYstem (ELSY) project of the European Community. These briefings occurred on November 13.

3) An initial meeting on the development of a Technology Pilot Plant/demo to serve the needs of both the European LFR program and the small transportable (SSTAR) system of the U.S. Generation IV program. This meeting took place on November 14.

LLNL staff prepared a journal article, jointly coauthored with staff from ANL, for publication in the Journal of Nuclear Materials. This paper was based on the presentations made at the ENEA-sponsored May 2007 meeting in Rome on Heavy Liquid Metal Coolant Technology. The paper is entitled "SSTAR: The US Lead-cooled Fast Reactor (LFR)".

LLNL staff provided input to the GIF-LFR-PSSC update briefing made to the GIF Experts and Policy Group meetings in Korea in November 2007.

LLNL staff provided inputs to the OECD/NEA Annual report summarizing GIF activities. 
LLNL staff participated in the planning, and organization of the March 2007 LFR-PSSC meeting in Paris.

LLNL staff provided inputs in response to comments on the May 2007 draft GIF System Research Plan of the Lead-cooled Fast Reactor; LLNL staff participated in the preparation of a major revision to this plan.

LLNL staff together with ANL staff participated in a panel session on Small- and Medium-sized (or "Grid Appropriate") Reactors for GNEP at Global 2007 in Boise ID on $9 / 12 / 07$. A presentation was given on lead-cooled reactor technology that included both the US GEN-IV LFR-SSTAR and the EU-ELSY concepts.

\subsection{ODS Steels in Corrosive Lead-Bismuth Eutectic}

Future LFR reactors will need fuel cladding materials that stand up to high temperatures in flowing lead-bismuth eutectic (LBE) or Pb. Several laboratories are working on the development of new steels with corrosion resistant properties. Research is focusing on ferritic/martensitic (F/M) steels and their oxide dispersion-strengthened (ODS) versions with low and high $\mathrm{Cr}$ concentration, with and without $\mathrm{Al}$ treatment.

\subsubsection{LBE-Cooled Fast Reactor Hot Spot Simulation: Low-Cr ODS Steels}

Oxide dispersion-strengthened steels are candidate materials for the fuel cladding of LBE-cooled fast reactors [1]. The effect on the cladding of changes in temperature and oxygen concentration that might occur during reactor operation has been investigated. To do this ODS steels were exposed to LBE for $4800 \mathrm{~h}$ with temperatures changing from 550 to $650{ }^{\circ} \mathrm{C}$ and back every $800 \mathrm{~h}$, see Figure $2-1$.
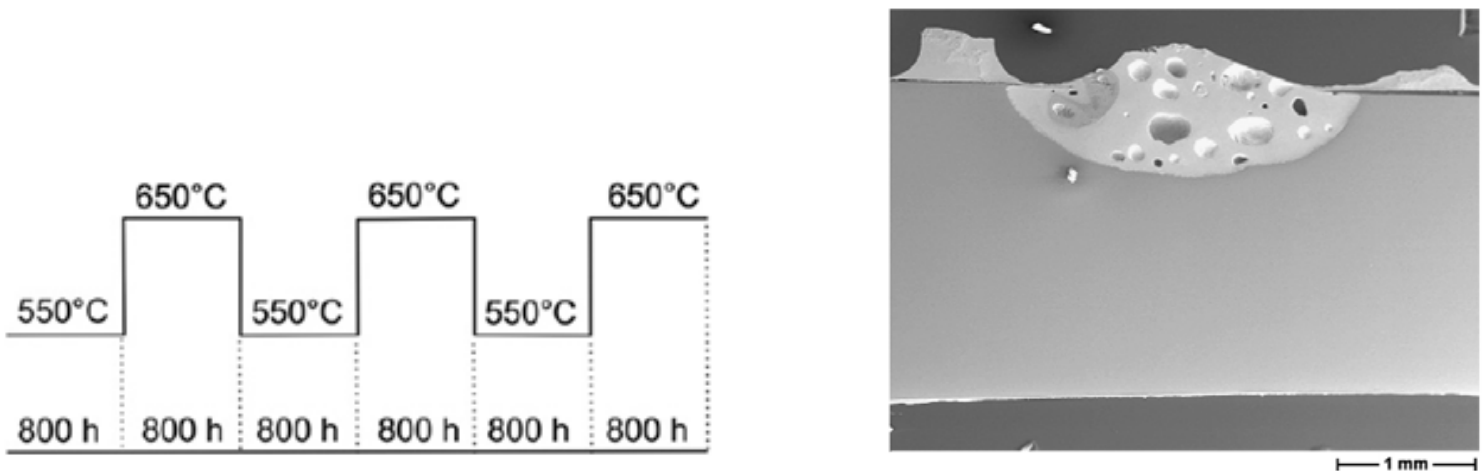

Figure 2-1. Hot spot simulation of temperature changes during LFR reactor operation, and SEM of ODS surface cross-section showing strong dissolution attack of the specimen exposed to LBE with $10^{-6}$ wt \% oxygen content for $4800 \mathrm{~h}$ at 550 $650{ }^{\circ} \mathrm{C}$ every $800 \mathrm{~h}$. 
Two experiments are reported: one with $10^{-6}$ and the other with $10^{-8} \mathrm{wt} \%$ oxygen in LBE. Both experiments show dissolution attack is less in LBE with $10^{-8} \mathrm{wt} \%$ oxygen and both experiments show strong local dissolution attack after $4800 \mathrm{~h}$. The authors conclude that dissolution attack of the $9 \mathrm{Cr}$ ODS cannot be prevented at $650{ }^{\circ} \mathrm{C}$.

\subsubsection{Improved Corrosion Resistance in Al-Diffusion Treated F/M Steels}

Good corrosion resistance was shown by a 14Cr-16Ni-2Mo (JPCA) F/M steel exposed to $\mathrm{LBE}$ at 450 and $550^{\circ} \mathrm{C}$ for $300 \mathrm{~h}$, see JPCA chemical composition in Table 2-1 [2].

Table 2-1. JPCA Chemical Composition

\begin{tabular}{llllllll}
\hline & $\mathrm{C}$ & $\mathrm{Cr}$ & $\mathrm{Ni}$ & $\mathrm{Mo}$ & $\mathrm{Fe}$ & $\mathrm{V}$ & $\mathrm{W}$ \\
\hline JPCA & 0.058 & 14.14 & 15.87 & 2.29 & Bal. & 0.003 & 0.01 \\
\hline
\end{tabular}

Gas diffusion treatment was done using $\mathrm{Al}$ compound powders $(\mathrm{FeAl}+\mathrm{Al} 2 \mathrm{O} 3)$ and $\mathrm{Ar}$ gas, and heating at $1100{ }^{\circ} \mathrm{C}$ for $10 \mathrm{~h}$. In the JPCA case, layers containing Al2O3, FeAl2, and $\mathrm{AlCr}_{2}$, were formed. The JPCA surface-treated steel exhibited corrosion resistance to LBE, see Figure 2-2. Optical micrograph of cross-sections of Al-diffusion-treated JPCA specimen after corrosion test in LBE at 450 and $550{ }^{\circ} \mathrm{C}$ for 3000 h.Figure 2-2. 

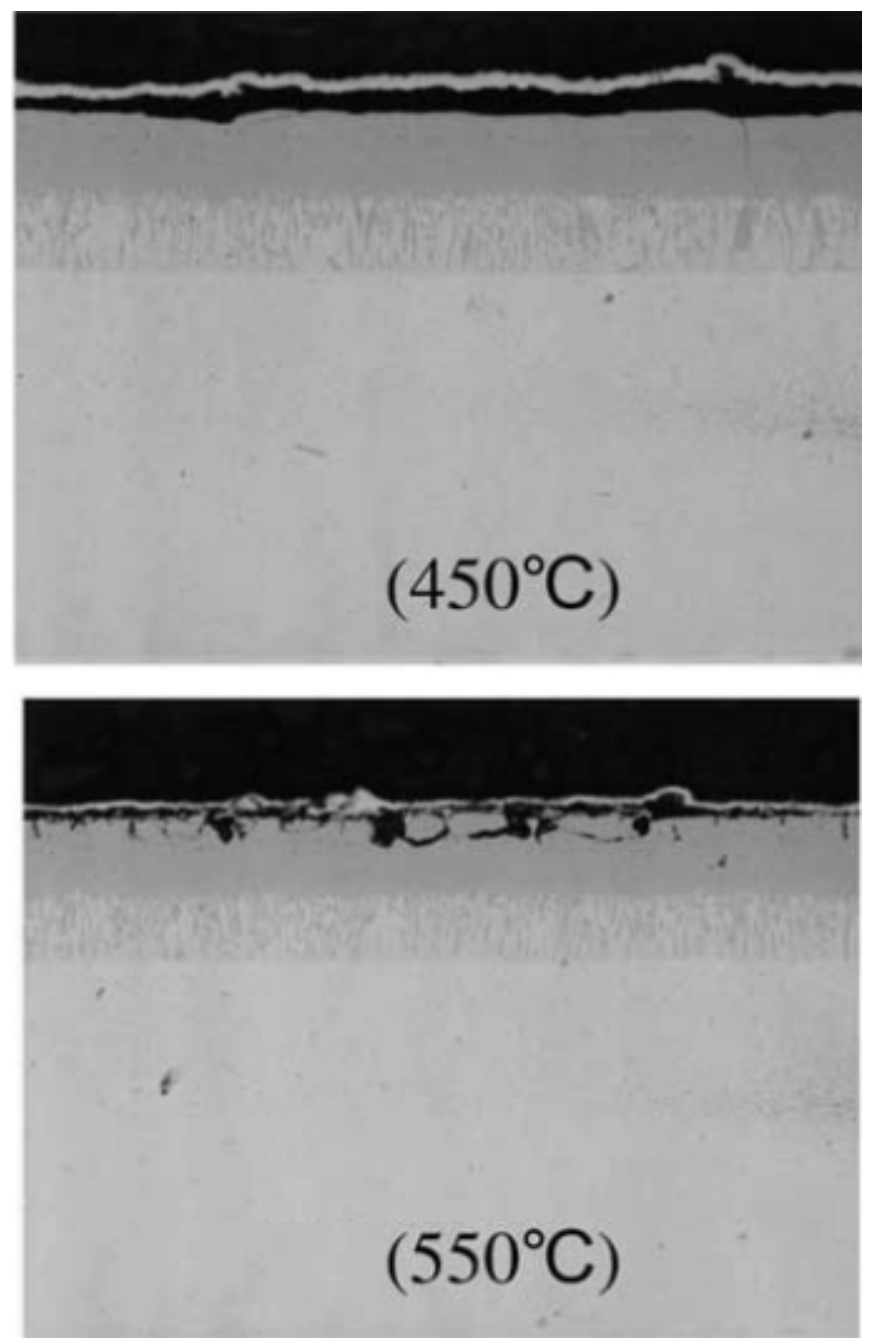

Figure 2-2. Optical micrograph of cross-sections of Al-diffusion-treated JPCA specimen after corrosion test in LBE at 450 and $550{ }^{\circ} \mathrm{C}$ for $3000 \mathrm{~h}$.

\subsubsection{Low-Cr ODS and F/M Steels with Modified Surface Structure}

A surface treatment "GESA" (pulsed electron beam) is applied to T91, E911, and ODS and samples are exposed to flowing LBE with $10^{-6} \mathrm{w} \%$ oxygen content at $550{ }^{\circ} \mathrm{C}$ for $2000 \mathrm{~h}$ [3]. The three steels show the same behavior: After exposure to LBE, a continuous oxide layer is formed, see Figure 2-3. The layer is of homogeneous thickness with the typical layered structure (outer layer: $\mathrm{Fe}_{3} \mathrm{O}_{4}$ porous magnetite layer, inner part of the oxide layer: Fe-Cr-O spinel, which sticks to the base materials and protects it from LBE corrosion). 

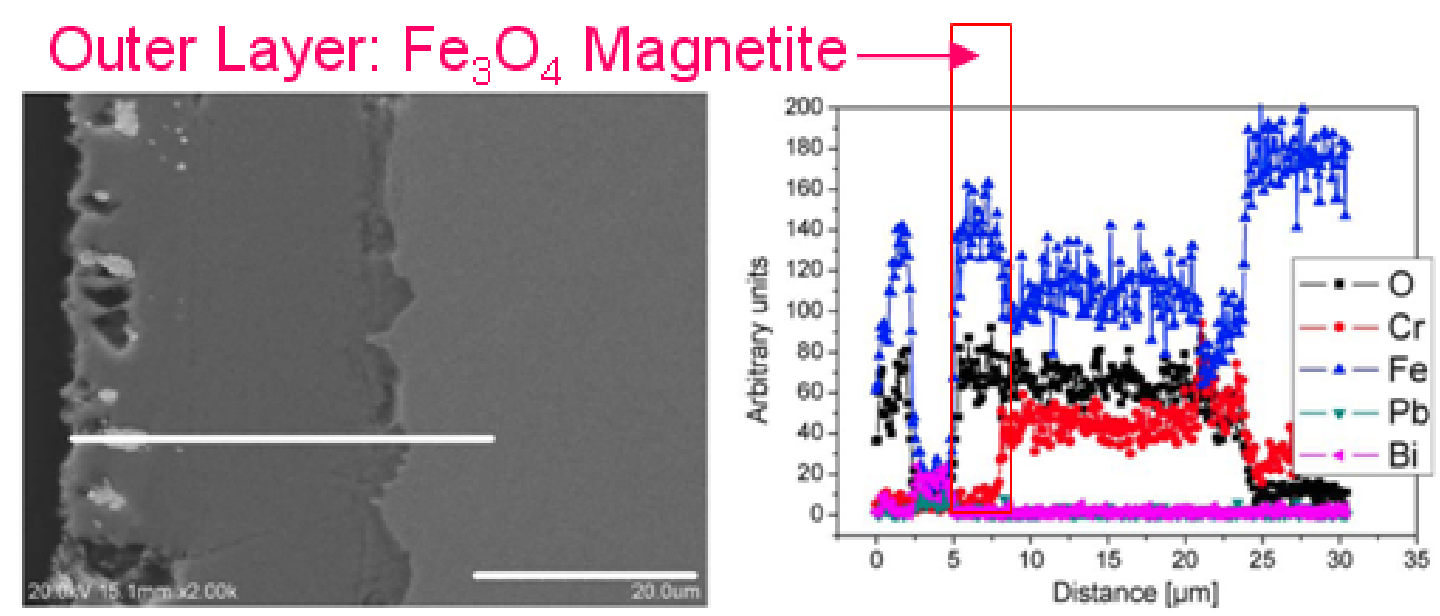

Figure 2-3. SEM cross section of GESA Surface Treated E911 specimen after exposure to flowing $\mathrm{LBE}\left(550{ }^{\circ} \mathrm{C}, 2000 \mathrm{~h}\right)$ and line scans of elements.

The results are of relevance in that it is found that in all these samples that underwent GESA surface treatment, the oxide layer "grows faster." The pulsed electron beam leads to a fine grained structure which influences the oxidation behavior. The smaller the grains, the larger the number of grain boundaries, which leads to higher diffusion rates resulting in an increased oxidation rate. The authors note that in the case of E911, the oxide layer grew up to 19-20 $\mu \mathrm{m}$ thick, T91 8-22 $\mu \mathrm{m}$, and 14-15 $\mu \mathrm{m}$ thick in ODS. Note, that a too thick oxide layer compromises the long-term stability (the oxide layer spalls).

In a second experiment, the authors placed an 18- $\mu$ m thick Al-foil on top of the steel surface and the GESA treatment was applied: The Al-foil melts and mixes together with the molten steel surface. This Al-surface alloying by GESA is not yet optimized. The foil was put by hand on the steel without any further fixing and therefore the resulting $\mathrm{Al}$ allocation is very inhomogeneous. However, the GESA Al coating shows promise. Experiments show three different behaviors depending on the Al content: 1) dissolution if the $\mathrm{Al}$ concentration is too high, 2) selective oxidations for $8<\mathrm{Al}<25 \mathrm{wt} \%$, and 3) normal steel oxidation, if the $\mathrm{Al}$ content is to low, i.e. the normal multi-layered oxides grow. Case 2) is relevant because a thin protective alumina $\left(\mathrm{Al}_{2} \mathrm{O}_{3}\right)$ layer grows at the places where $\mathrm{FeAl}$, and/or $\mathrm{FeAl}, \mathrm{AlCr}_{2}$ are formed.

\subsubsection{Corrosion Resistant High-Cr ODS Ferritic Steels}

ODS ferritic steels have been developed by the Japan Atomic Energy Agency (formerly Japan Nuclear Cycle Development Institute, JNC) and KOBELCO [4]. At present, a ton ball mill for mechanical alloying is available to produce $\sim 200$ fuel pins $3 \mathrm{~m}$ in length. These ODS steels, which contain 9-12Cr \%, have shown high resistance to neutron embrittlement in the irradiation experiments carried out in the experimental fast reactor JOYO in 2007 [5]. In these experiments, ODS cladding tube specimens $(75 \mathrm{~mm}$ in length) were irradiated in the experimental fast reactor JOYO at temperatures between 
723 and $878{ }^{\circ} \mathrm{K}$ to fast neutron fluences $(\mathrm{E}>0.1 \mathrm{MeV})$ from 2.1 to $4.2 \times 10^{26} \mathrm{n} / \mathrm{m}^{2}$. However, they fail when exposed to lead at high temperatures. High-Cr ODS steels with better corrosion resistance properties have been developed at Kyoto University [6].

With a budget of $13 \mathrm{M} \$$ for 5 years, the R\&D program on "High Performance Advanced Ferritic Steel" is taking the lead in this area in Kyoto University, Japan. The fabrication of high temperature strength materials that are corrosion and irradiation resistant is a targeted goal for the next generation of nuclear systems. The R\&D program has focused on Generation IV nuclear energy systems highly efficient and with high-burn-up operation ( $>100 \mathrm{GWd} / \mathrm{t}$ ); see the supercritical-water-cooled reactor (SCWR) and LFR in the figure below.

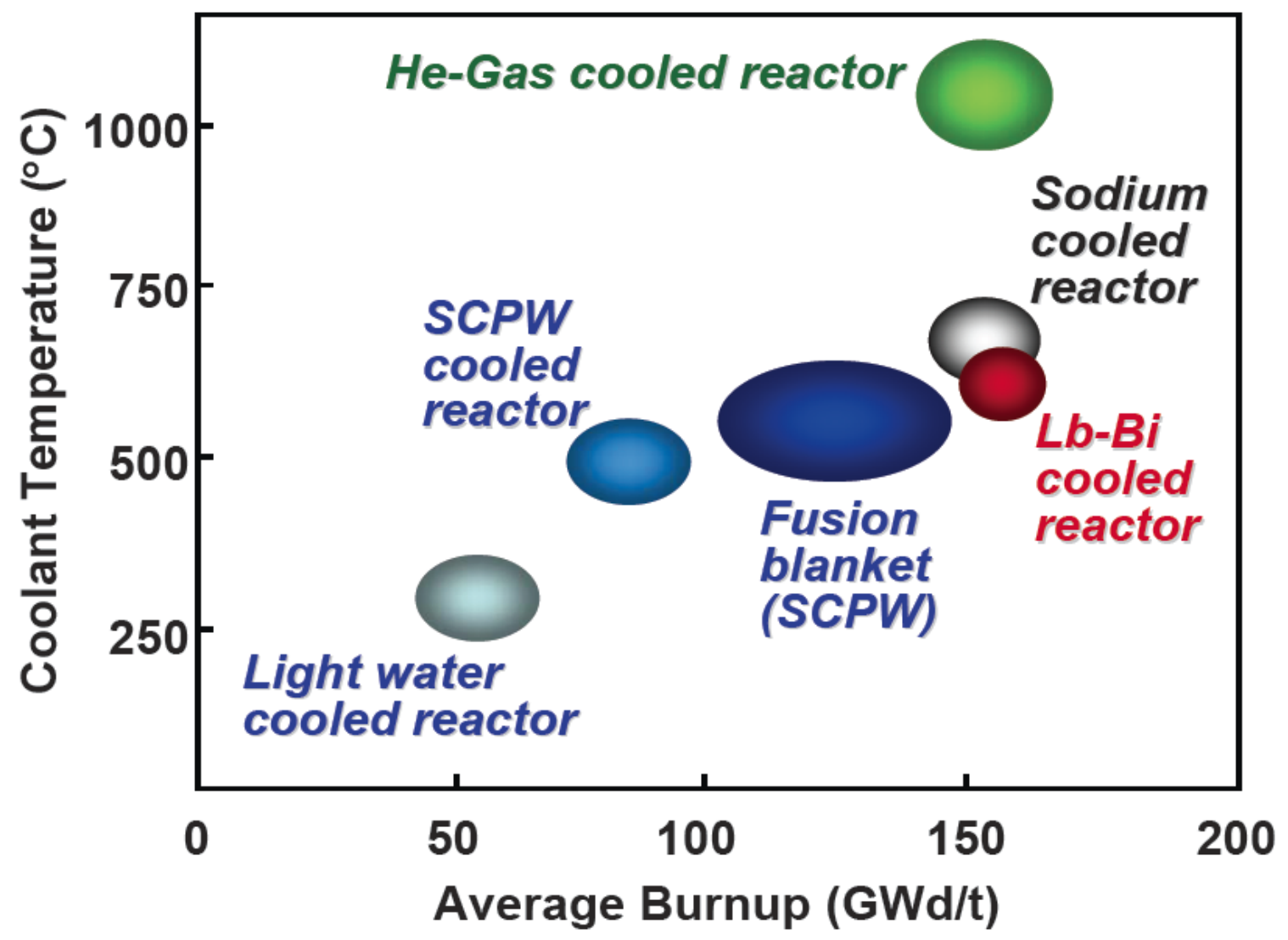

Figure 2-4. Coolant Temperature/Burnup of Next Generation Nuclear Systems, taken from [7].

Low activation nano-sized ODS steels that contain a fine distribution of YttriumAluminum oxides have been developed at Kyoto University and are under consideration among the preferred cladding of future highly efficient and advanced nuclear power plants. Basic properties of high-Cr ODS steels, i.e. steels with 13, 16, 19 and $22 \mathrm{wt} \% \mathrm{Cr}$ and $4.5 \% \mathrm{Al}$, have been evaluated and are reported in Reference [6]. Results of corrosion resistance in SCPW $\left(783{ }^{\circ} \mathrm{K}, 25 \mathrm{MPa} .600 \mathrm{~h}\right.$ and $\left.1200 \mathrm{~h}\right)$, thermal aging 
embrittlement $\left(500{ }^{\circ} \mathrm{C}, 1000 \mathrm{~h}\right)$, ion irradiations $\left(573,773\right.$, and $973{ }^{\circ} \mathrm{K}$ up to $\left.20 \mathrm{dpa}\right)$, harndess measured via nano-indentation, etc. show that these high-Cr ODS steels have high potential as LFR fuel cladding materials.

In particular, LBE corrosion resistance was demonstrated. The new 19Cr-4Al-ODS steel showed no corrosion when exposed for $10,000 \mathrm{~h}$ to $\mathrm{LBE}$ at $650{ }^{\circ} \mathrm{C}$ with $10^{-6} \mathrm{wt} \%$ opxygen. This was not the case of 9Cr-ODS steel, see Figure 2-5.
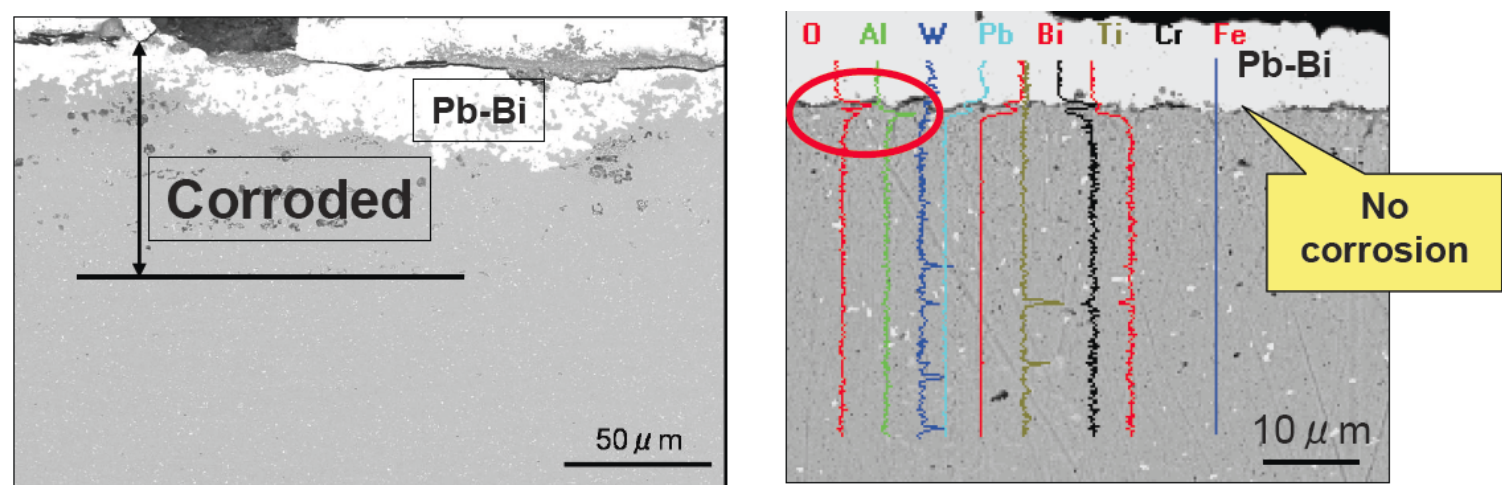

Figure 2-5. Corrosion resistance of high-Cr ODS steel (19Cr-4Al) at high temperature $\left(650{ }^{\circ} \mathrm{C}\right)$ exposed to $\mathrm{LBE}$ for $10,000 \mathrm{~h}$ with an oxygen content of 10-6 $\mathrm{Wt} \% \mathrm{O}_{2}$, taken from Reference [7].

The addition of Aluminum to the ODS chemical composition leads to the formation of A12O3 alumina and enhances the LBE corrosion resistance of the materials. Note that the ductile-to-brittle transition temperature (DBTT) increases with increasing $\mathrm{Cr}$ and that the addition of $\mathrm{Al}$ decreases the tensile strength of the ODS steel. Finally, long term experiments (neutron irradiation, creep tests, and long-lasting corrosion experiments) are still needed to confirm the performance of this kind of Super ODS Steel.

\subsection{References}

1. A. Weisenburger, K. Aoto, G. Muller, A. Heinzel, G. Schumacher, T. Furukawa, "Behaviour of chromium steels in liquid $\mathrm{Pb}-55.5 \mathrm{Bi}$ with changing oxygen content and temperature", JNM 358 (2006) 69-76.

2. Y. Kurata, M. Futakawa, S. Saito, "Corrosion behavior of Al-surface-treated steels in liquid Pb-Bi in a pot", JNM 335 (2004) 501-507.

3. A. Heinzel, M. Kondo, M. Takahashi, "Corrosion of steels with surface treatment and Al-alloying by GESA exposed in lead-bismuth”, JNM 350 (2006) 264-270.

4. S. Ukai, S. Mizuta, T. Yoshitake, et al. "Tube manufacturing and characterization of ODS ferritic steels" JNM 283-287 (2000) 702-706. 
5. T. Yoshitake, T. Ohmori, S. Miyakawa, "Burst properties of irradiated oxide dispersion strengthened ferritic steel claddings", JNM 307-311 (2002) 788.

6. A. Kimura, H-S Cho, N. Toda, R. Kasada, K. Yutani, H. Kishimoto, N. Iwata, S. Ukai, M. Fujiwara, "High Burnup Fuel Cladding Materials R\&D for Advanced Nuclear Systems: Nano-sized oxide dispersion strengthening steels", J. of Nucl. Sci. and Tech. 44 (2007) 323.

7. A. Kimura, H.S. Cho, N. Toda, R. Kasada, H. Kishimoto, N. Iwata, S. Ukai and M. Fujiwara, "High Burnup Fuel Cladding Materials R\&D for Water-cooling Nuclear Power Plants-Nano-sized ODS Steels", 2006 MRS Fall Meeting Nov. 27-Dec. 1, 2006, Boston.

\section{Los Alamos National Laboratory}

\subsection{Introduction}

For FY 2008, the following has been accomplished:

1) Published or submitted 5 papers to the Journal of Nuclear Materials on analyses of LBE corrosion of steels based on DELTA testing;

2) Completed an analysis of a DELTA loop experiment on the efficacy of using solid $\mathrm{PbO}$ to control coolant chemistry, and prepared a technical report;

3) Received the SMARTGARD circuit breakers to replace the existing ones (under-rated for DELTA use, causing frequent heater trippings);

4) An experimental study at LANL on the effects of oxygen on LBE heat transfer has led the Eurotrans ADS design team to reconsider safety margins and design strategies to mitigate the reduction of heat transfer by fouling and oxides;

5) Applied the corrosion-oxidation model to available test data and classified the corrosion performance in $\mathrm{LBE}$ and $\mathrm{Pb}$ of some candidate steels.

\subsection{Published or Submitted Papers}

A number of advanced microscopic methods (Atomic Force Microscopy (AFM), Magnetic Force Microscopy (MFM), Conductive-AFM (C-AFM), Transmission Electron Microscopy (TEM), and nano-scale characterization have been applied to analyze the DELTA and IPPE-loop tested specimens. These methods have revealed significantly more detailed microstructure and composition information that are absent in more traditional SEM analysis. In particular, it was possible to identify the non-conductive layers of oxides that are believed to offer the main corrosion protection. In addition to obtaining a fundamental understanding, such information is useful when long-life cores (20-30 years services) are considered. 
These following results are published or submitted in FY08 in the paper:

P. Hosemann, H.T. Thau, A. L. Johnson, S. A. Maloy, N. Li, "Corrosion of ODS Steels in Lead-Bismuth-Eutectic,” J. Nuc. Mater. 373 (2008) 246.

Oxide dispersion-strengthened (ODS) ferritic steels are advanced materials being developed for high temperature applications. Their properties (high temperature strength, creep resistance, corrosion/oxidation resistance) make them potentially usable for high temperature applications in liquid metal-cooled systems like liquid lead-bismuth eutectic cooled reactors and spallation sources. Corrosion tests on five different ODS alloys were performed in flowing liquid lead-bismuth eutectic in the DELTA Loop at the Los Alamos National Laboratory at $535^{\circ} \mathrm{C}$ for $200 \mathrm{~h}$ and $600 \mathrm{~h}$. The tested materials were chromium-alloyed ferritic/martensitic steels (12YWT, 14YWT, MA957) and $\mathrm{Cr}-\mathrm{Al}$ alloyed steels (PM2000, MA956). It was shown that the Al-alloyed ODS steel above 5.5 wt \% $\mathrm{Al}$ (PM2000) is highly resistant to corrosion and oxidation in the conditions examined, and that the corrosion properties of the ODS steels depend strongly on their grain size.

The following work is reported in the paper,

P. Hosemann, J. G. Swadener, J. Welch, N. Li, "Nano-indentation Measurement of oxide layers formed in LBE on F/M Steels," in press, J. Nuc. Mater. doi:10.1016/j.jnucmat.2008.02.073.

Ferritic/martensitic (F/M) steels (T91, HT-9, EP 823) are candidate materials for future liquid lead- or LBE-cooled nuclear reactors. To understand the corrosion of these materials in LBE, samples of each material were exposed at $535^{\circ} \mathrm{C}$ for $600 \mathrm{~h}$ and $200 \mathrm{~h}$ at an oxygen content of $10^{-6} \mathrm{wt} \%$. After the corrosion tests, the samples were analyzed using SEM, WDX and nano-indentation in cross section. Multi-layered oxide scales were found on the sample surfaces. The compositions of these oxide layers are not entirely in agreement with the literature. The nano-indentation results showed that the Emodulus and hardness of the oxide layers are significantly lower than the values for dense bulk oxide materials. It is assumed that the low values stem from high porosity in the oxide layers. Comparison with in-air oxidized steels show that the E-modulus decreases with increasing oxide layer thickness.

The following results are reported in

P. Hosemann, M. Hawley, G. Mori, N. Li, S. A. Maloy, "AFM and MFM characterization of oxide layers grown on stainless steels in lead bismuth eutectic", in press, J. Nuc. Mater. Doi: 10.1016/j.jnucmat.2008.02.013.

Fast reactors and spallation neutron sources may use LBE as a coolant. Its thermal physical and neutronic properties make it a high performance nuclear coolant and spallation target. The main disadvantage of LBE is that it is corrosive to most steels and 
container materials. Active control of oxygen in LBE will allow the growth of protective oxides on steels to mitigate corrosion. To understand corrosion and oxidation of candidate materials in this environment and to establish a solid scientific basis the surface structure, composition, and properties should be investigated carefully at the smallest scale. Atomic Force Microscopy (AFM) is a powerful tool to map out properties and structure on surfaces of virtually any material. The paper is a summary of the results from AFM measurements on ferritic/martensitic (HT-9) and austenitic (D9) steels that are candidates for liquid metal cooled reactors.

The following results are reported in the paper,

P. Hosemann, M.E. Hawley, D. Koury, J. Welch, A.L. Johnson, G. Mori, N. Li, S.A. Maloy, "Nanoscale Characterization of HT-9 Exposed to Lead Bismuth Eutectic at $550^{\circ} \mathrm{C}$ for 3000 h", submitted and accepted, J. Nuc. Mater.

Fast reactors and targets in spallation neutron sources may use LBE as a coolant. Its physical and chemical properties and irradiation properties make it a safe and high performance coolant in radiation environments. However, LBE is a corrosive medium for most steels. In the present study, the atomic force microscopy, magnetic force microscopy, conductive atomic force microscopy, surface potential microscopy, and scanning electron analysis with energy dispersive x-ray spectroscopy were performed to get a better understanding of the corrosion and oxidation mechanism of HT-9 steel in an LBE environment. What was believed in the past to be simply a double oxide layer structure was revealed here to be more complicated. It is found that the innermost oxide layer maintains the grain structure of what used to be the bulk steel material while the outer oxide layer possessed a columnar structure. The EDS line scans and the conductive and magnetic properties measured using the scanning probe techniques give us the local properties of the formed oxide layers. This leads to a more detailed view of the oxide layers formed on HT-9 in LBE.

The following is reported in the paper,

P. Hosemann, M. Hawley, D. Koury, J.G. Swadener, J. Welch, A. L. Johnson, G. Mori, N. Li, "Nanoscale characterization of oxide layers formed on D9 stainless steel in LBE environment", in press, J. Nuc. Mater. doi:10.1016/j.jnucmat.2007.12.005.

Lead bismuth eutectic is a possible coolant for fast reactors and targets in spallation neutron sources. Its low melting point, high evaporation point, good thermal conductivity, low reactivity, and good neutron yield make it a safe and high performance coolant in radiation environments. The disadvantage is that it is a corrosive medium for most steels and container materials. This study was performed to evaluate the corrosion behavior of the austenitic stainless steel, D9, in oxygen-controlled LBE. In order to predict the corrosion behavior of steel in this environment, detailed analyses have to be performed on the oxide layers formed on these materials and various other relevant materials upon exposure to LBE. In this study the corrosion/oxidation of D9 stainless steel in LBE was investigated in great detail. The oxide layers formed were characterized 
using atomic force microscopy, magnetic force microscopy, nanoindentation, and scanning electron microscopy with wavelength-dispersive spectroscopy (WDS) to understand the corrosion and oxidation mechanisms of D9 stainless steel in contact with the LBE. What was previously believed to be a simple double oxide layer was identified here to consist of at least 4 different oxide layers. It was found that the innermost oxide layer takes over the grain structure of what used to be the bulk steel material while the outer oxide layer consists of freshly grown oxides with a columnar structure. These results lead to a descriptive model of how these oxide layers grow on this steel under the harsh environments encountered in these applications.

\subsection{DELTA PbO Experiment}

The experiments were conducted in May 2007. A PbO pellet holder was built and installed in a bypass section of DELTA (inlet after pump discharge, before recuperator, and outlet before heat exchanger, at the low temperature section). The bypass section is cooled by flowing water in copper tubing coiled around the pipe, and heated by taped heaters. The LBE flow through bypass is controlled by manual valves at both ends of the bypass.

Three thermocouples monitored the temperature distribution in the bypass, and four oxygen sensors in the main flow sections of DELTA measured the changes in oxygen concentrations in LBE.

The experiments successfully demonstrated effective addition of oxygen into LBE, but the effect of oxygen removal might have been masked by residual excess oxygen in the cover gas of the sump tank from our operation. There was difficulty in lowering the LBE temperature in the bypass because the insufficient cooling capacity of the flowing water. For reliable implementation in DELTA and LBE facilities, further design and engineering development will be needed. However, the feasibility of such an approach has been established.

The results and analysis are summarized in a technical report, "Experiments on the Efficacy of Solid PbO Addition and Precipitation for Oxygen Control in the DELTA Loop at Los Alamos National Laboratory."

\subsection{Effects of Oxides on Steels and Oxygen in LBE on Heat Transfer}

In a recent Eurotrans DEMETRA $3^{\text {rd }}$ Year Annual Review Meeting (March 4-7, 2008), Dr. S. Stuwe of the Forschungszentrum Karlsruhe in the ADS design team presented "Important issues on $\mathrm{Pb}$ and $\mathrm{PbBi}$ coolants for design and safety optimization." It cited the LANL work on the effects of oxides on steels and oxygen in LBE on heat transfer (F. Niu, R. Candalino, N. Li, "Effect of Oxygen on Fouling Behavior in Lead-Bismuth Coolant Systems", Journal of Nuclear Materials, Vol. 366, Iss. 1-2, 216-222,2007). 
Some scoping studies were performed by the Eurotrans project based on the fouling factor that the LANL DELTA experiment showed. For normal operating conditions where the oxygen concentration in LBE is maintained near $10^{-6} \mathrm{wt} \%$, the effect is small. However, in cases where the oxygen concentration approaches the saturation limit, the fouling effect can be very significant. For oxides on steels from corrosion protection, thicknesses beyond several tens of microns can raise the fuel pin/clad temperature rather significantly (for ADS blanket, approximate $1{ }^{\circ} \mathrm{C} /$ micron at the hot spots).

These design studies show the importance of understanding the effects of oxides on steels and oxygen in LBE on heat transfer. Further experimental investigation is warranted.

\subsection{Long-Term Oxidation/Corrosion Performance of Candidate Steels in LBE and $\mathbf{P b}$}

Using the systematic oxidation/corrosion kinetics model we developed, and the reported experiment test data for a number of candidate steels in LBE and $\mathrm{Pb}$, we derived a set of classification of the long-term behaviors. The results will be published in the near future.

In Figure 3-1, it is seen that a number of steels will have asymptotic oxide thicknesses below 30-40 microns, which may be susceptible to spalling. However, the ones that approach asymptotic behaviors very quickly have relatively high liquid metal corrosion rates (through the oxides). EP823 is clearly the top performing material under this condition. 


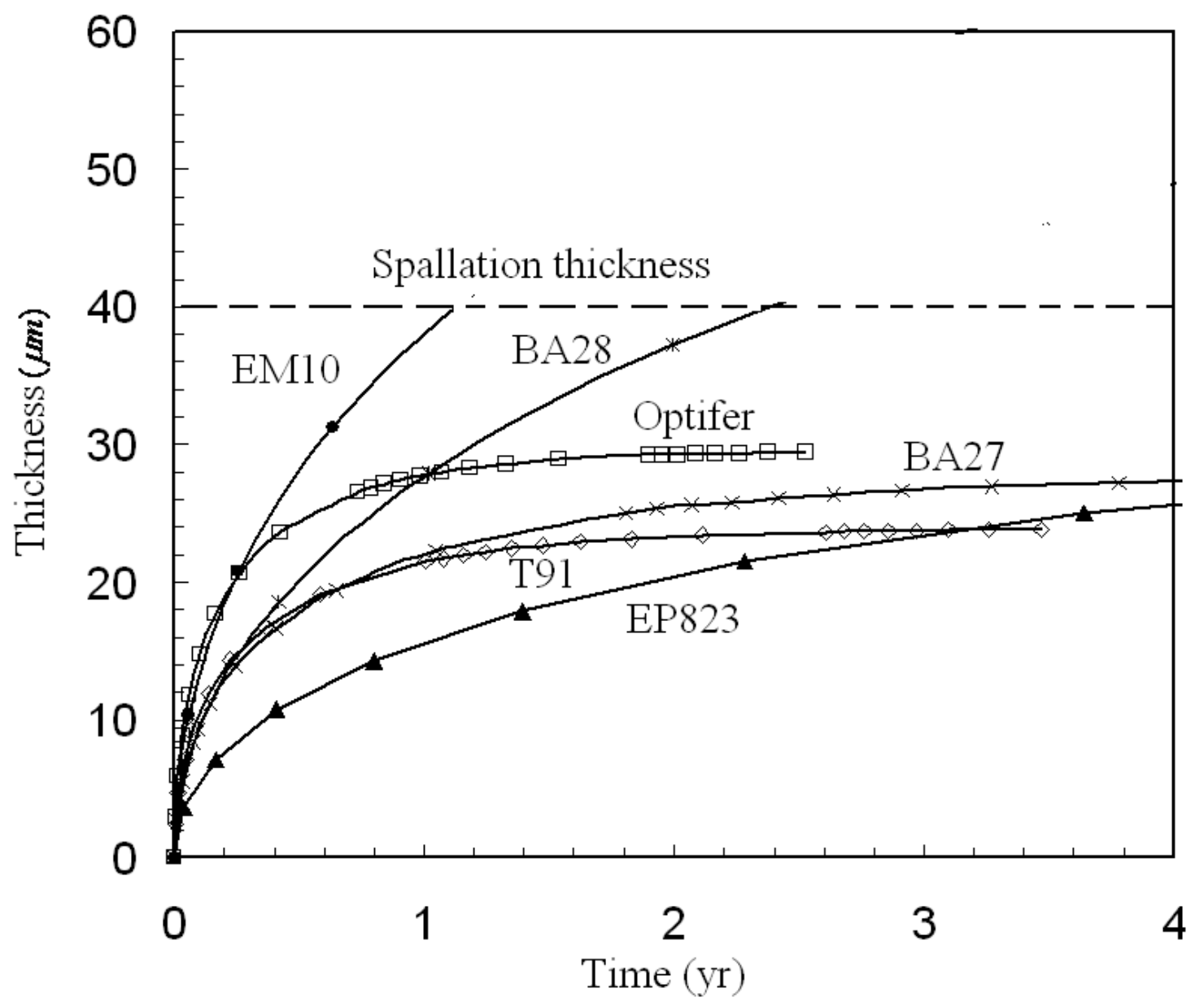

Figure 3-1. Long-Term Behavior of Steels in Flowing LBE with a Velocity of $1 \mathrm{~m} / \mathrm{s}$, an Oxygen Concentration of 0.01-0.02 ppm, and a Temperature of $470{ }^{\circ} \mathrm{C}$.

In Figure 3-2, it is found that HT-9, DIN1.4790 and D9 will grow very thick oxides within a year in LBE at $550{ }^{\circ} \mathrm{C}$. While $316 \mathrm{SS}$ has oxides that stay relatively thin, they can suffer from local corrosion that is much more substantial than the general oxidation/corrosion. The long-term test data will be analyzed when they become available. 


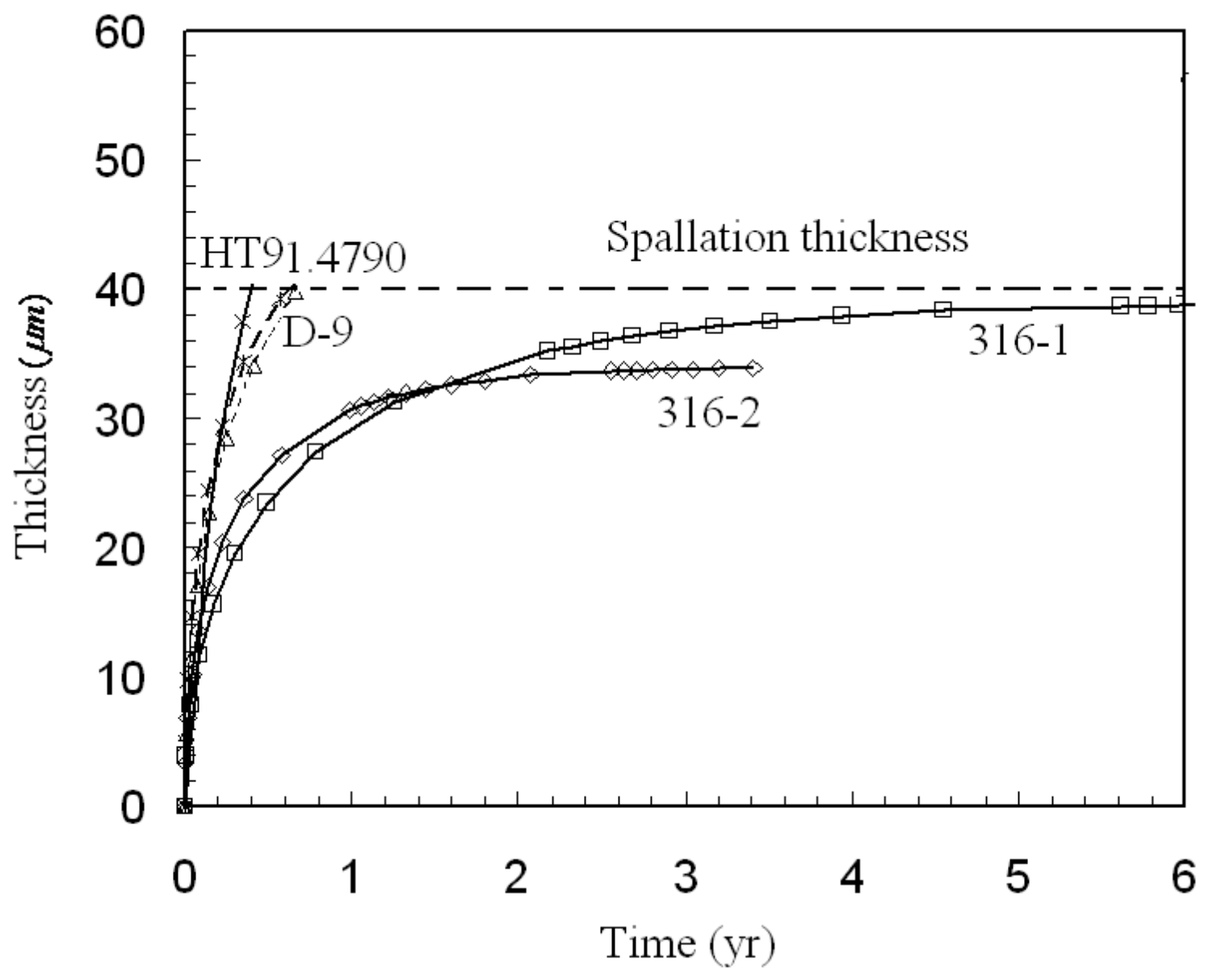

Figure 3-2. Long-Term Behavior of Steels given in LBE at a Velocity of 1.9 and 0.5 $\mathrm{m} / \mathrm{s}$, an Oxygen Concentration of 0.01, 0.02-0.03 ppm, and a Temperature of $550{ }^{\circ} \mathrm{C}$.

\section{Acknowledgements}

This work was supported by the Generation IV Nuclear Energy Systems Initiative. The authors are indebted to Dr. Rob M. Versluis, the U.S. DOE Generation IV Program Manager, for his continued support while the LFR was still part of the Generation IV Initiative. The authors are also grateful to Drs. Luciano Cinotti (Del Fungo Giera Energia S.p.A) and Stefano Monti and Carlo Artioli (ENEA) for discussions and information concerning the Technology Pilot Plant and ELSY. 
Argonne

Nuclear Engineering Division

Argonne National Laboratory

9700 South Cass Avenue, Bldg. 208

Argonne, IL 60439-4842

www.anl.gov

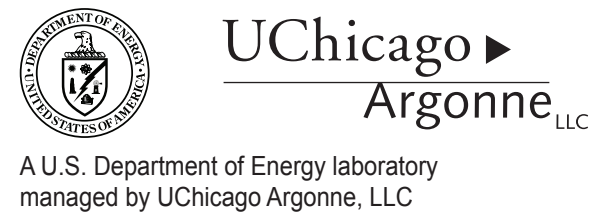

